\title{
Rational Management of Didymella rabiei in Chickpea by Integration of Genotype Resistance and Postinfection Application of Fungicides
}

\author{
D. Shtienberg, H. Vintal, S. Brener, and B. Retig
}

First and second authors: Department of Plant Pathology; third and fourth authors: Department of Field Crops, Agricultural Research Organization, The Volcani Center, P.O. Box 6, Bet-Dagan 50250, Israel. Accepted for publication 13 April 2000.

\begin{abstract}
Shtienberg, D., Vintal, H., Brener, S., and Retig, B. 2000. Rational management of Didymella rabiei in chickpea by integration of genotype resistance and postinfection application of fungicides. Phytopathology 90:834-842.

Various aspects of the integration of genotype resistance and chemical control of Ascochyta blight (caused by Didymella rabiei) in chickpea were examined in field experiments from 1993 to 1999 and in greenhouse experiments. Four commercially available chickpea cultivars representing a range of resistance to $D$. rabie $i$ were used. The efficacy of chemical control in a highly susceptible cultivar was significantly $(P<0.01)$ related to the conduciveness of the environment to the pathogen. Adequate disease suppression (>80\% control) was achieved when weather supported mild epidemics, but insufficient control $(<20 \%)$ was achieved when weather supported severe epidemics. The contribution of genotype resistance to disease suppression in a moderately susceptible cultivar varied from $<10 \%$ when weather supported severe epidemics to $\approx 60 \%$ when weather supported mild epidemics. Spraying a moderately resistant cultivar resulted in $95 \%$ control when weather supported mild epidemics,

resulted in $70 \%$ control when weather supported severe epidemics; fungicides improved control efficacy significantly to $>95 \%$. Under mild epidemics, moderate resistance alone provided $>95 \%$ control. The level of genotype resistance available in a highly resistant cultivar was sufficient to suppress the disease under all weather conditions, even without application of fungicides. The possibility of relying on postinfection rather than prophylactic application of fungicides was tested in the greenhouse and in four field experiments. Activity of the systemic fungicide tebuconazole was detected when the fungicide was applied up to 3 days postinfection, and application of tebuconazole or difenoconazole in the field as a postinfection treatment (i.e., after rain or overhead irrigation) suppressed the disease as effectively as preventive applications and required fewer sprays. In two experiments, the interaction between genotype resistance and chemical control at various amounts of irrigation applied via overhead sprinklers (as a simulation of rain) was tested. The results show that both the level of genotype resistance and the quantity of water should be taken into account in deciding whether to apply a postinfection spray.
\end{abstract} but only $65 \%$ control was achieved when weather supported severe epidemics. The existing level of resistance in a moderately resistant cultivar
Additional keywords: epidemiology, IPM, legume crops, systemic fungicides.
Chickpea (Cicer arientinum L.) is the third most important food legume in the world after dry bean and pea. In 1988, 10 million hectares of chickpea worldwide were cultivated to produce a yield of $\approx 7$ million metric tons (5). In the west Asian, Mediterranean Basin, and North African regions, chickpea accounts for more than $27 \%$ of total food legume production $(1,17)$. Despite the importance of the crop, most farmers in these regions are still growing unimproved land races or local cultivars in spring-sown crops, with small yields averaging $700 \mathrm{~kg} / \mathrm{ha}(5,25)$. Winter sowing, because of winter rains and mild temperatures favoring a longer vegetative and reproductive period, can significantly increase these yields $(12,18,20)$. In a study conducted in Syria and Lebanon over a 10-year period, winter-sown chickpea produced $70 \%$ more seed yield than the spring-sown crop, and yields were more stable (25). In Israel, winter sowing of chickpea has been practiced for $\approx 30$ years. Seeds are sown in mid-winter (December to January), and the crop matures and is harvested in early summer (June to July); yields generally range from 2,500 to $4,000 \mathrm{~kg} / \mathrm{ha}$, and larger yields are not uncommon. One factor that precludes winter sowing in the Mediterranean region and imposes yield losses on the winter crops in Israel is the prevalence of diseases, especially Ascochyta blight $(5,12,17,20,25)$.

Corresponding author: E-mail address: danish@ @etvision.net.il

Publication no. P-2000-0605-01R

(๖) 2000 The American Phytopathological Society
Ascochyta blight, caused by Didymella rabiei (Kovacheski) v. Arx. (anamorph Ascochyta rabiei (Pass.) Labr.) is one of the most important diseases of chickpea in many countries of south Asia, the Middle East, the Mediterranean region, and North Africa $(1,10,13,14)$. The pathogen can infect all aboveground plant parts at any stage of crop development, leading to rapid tissue collapse and spread of necrotic lesions. Yield losses may reach $100 \%$ under favorable environmental conditions $(10,12)$. Like many other pycnidial fungi, the pathogen is spread mainly by rain splash of pycnidiospores $(2,6,16)$. Although temperature and wind influence disease development and spread, rainfall is probably the critical factor in most epidemics, and the disease develops whenever there are rains during the cropping season $(1,4,5,12,14,18,28)$.

The use of resistant cultivars is the most effective and economical strategy for management of Ascochyta blight $(1,14)$. However, the level of resistance present in the cultivated germ plasm in many countries is not sufficient to withstand high disease pressure when conditions are favorable for the pathogen (1). Moreover, the effectiveness of genotype resistance is limited by the considerable variation in pathogenicity in the fungal population. Disease intensity may be suppressed by foliar application of fungicides, including Bordeaux mixture, wettable sulfur, zineb, maneb, captan, and chlorothalonil $(8,13,26)$. Nevertheless, chemical control is not widely used against Ascochyta blight for two reasons. First, the fungicides with known efficacy against the pathogen are preventive; therefore, prophylactic spraying should be attempted before the occurrence of infections. For winter-sown crops, up to 12 sprays should be applied for season-long protection (18). Second, 
the available preventive fungicides generally are ineffective when applied to susceptible cultivars during severe epidemics $(1,13)$.

Under present circumstances, when host resistance is unstable and the effectiveness of chemical control is low, an integrated disease management approach should be followed. This approach requires a shift from total reliance on host plant resistance to other ways of managing disease, such as complementary use of chemicals (1). A few studies have been completed on the use of fungicides and host resistance in the management of Ascochyta blight. Reddy and Singh (19) studied the potential for integration of host plant resistance and a limited number of foliar sprays and found that two foliar sprays of chlorothalonil on a moderately resistant cultivar at seedling and early podding stages were most cost-effective.

The efficacy of systemic fungicides against $D$. rabiei has not yet been reported. These fungicides penetrate into the host tissue, and consequently, some of them possess postinfection properties that may enable them to be applied after the occurrence of infections and still prevent the appearance of disease symptoms. Postinfection application of systemic fungicides has been effective in several pathosystems, e.g., in the management of Septoria glume and leaf blotch (caused by Leptosphaeria nodorum and Mycosphaerella graminicola, respectively) in wheat $(3,23)$, apple scab (caused by Venturia inaequalis) in apple (21), and anthracnose (caused by Colletotrichum spp.) in mango (7). Because pycnidiospores of D. rabiei are dispersed in rain or in overhead irrigation droplets and because infections occur shortly after, it is hypothesized that application of a systemic fungicide with postinfection properties soon after spore dispersal would enable Ascochyta blight to be managed. Furthermore, application of systemic fungicides to moderately resistant cultivars may result in adequate disease suppression, even when weather is conducive for the pathogen, as often happens during winter cropping. The number of fungicidal sprays needed is expected to be limited, because rain episodes are scarce in the late winter and early spring season in the Middle East.

Our goal is to identify general principles and specific approaches for cost-effective management of Ascochyta blight in wintersown chickpea. This investigation has two major objectives: to quantify the relative contributions of genotype resistance and chemical control in disease suppression and to test the efficacy of postinfection applications of systemic fungicides in cultivars with different levels of genotype resistance. The effects of the treatments on yield are not addressed and will be discussed elsewhere. We assumed that better disease suppression is advantageous over less effective disease suppression. This assumption is based on an inverse linear relationship observed between disease intensity and yield (D. Shtienberg and B. Retig, unpublished data).

\section{MATERIALS AND METHODS}

Cultural practices. Various aspects related to integration of genotype resistance and chemical control of Ascochyta blight in chickpea were examined in field experiments from 1993 to 1999 and in greenhouse experiments. Field experiments were conducted at The Volcani Central Experimental Station, Bet Dagan, on the coastal plain of Israel. Four chickpea cultivars currently available in commercial production and representing a range of resistance to D. rabiei were used: Sfaradit is highly susceptible, Ayala is moderately susceptible, Hadas is moderately resistant, and Bulgarit is highly resistant. Cvs. Hadas and Ayala were developed in Israel, and Sfaradit and Bulgarit are unidentified cultivars introduced from Spain and Bulgaria, respectively. The response of the cultivars was determined in artificially inoculated field experiments prior to 1993 and confirmed in the present study.

Seeds were machine planted in middle to late December 1992 to 1998 for the corresponding 1993 to 1999 growing seasons. Al- though chickpea was not the crop grown immediately prior to either experiment, D. rabiei-infected crops had been grown in the experimental site for several years. The distance between rows was $0.5 \mathrm{~m}$, and plants were spaced 6 to $8 \mathrm{~cm}$ apart within rows. If not otherwise specified, each experimental plot was $2 \mathrm{~m}$ wide and $9 \mathrm{~m}$ long. Experimental plots were separated by $1.5 \mathrm{~m}$ laterally and $2.5 \mathrm{~m}$ longitudinally. In most experiments, a row of susceptible cv. Sfaradit was planted between experimental plots. These plants were inoculated artificially and served to spread the disease to the adjacent plots. An overhead irrigation system was installed and used, when needed, to spread the pathogen from spreader rows to experimental plots and to enhance disease severity during periods of drought. Preparation of the land and fertilization and application of herbicides and insecticides were done as recommended to chickpea growers in Israel. Fungicides were applied only for management of D. rabiei, as outlined below.

The preventive fungicide maneb and the systemic fungicides tebuconazole and difenoconazole were applied in all experiments. Maneb (Manebgan, 50\% FC) was applied at a rate of 1,250 $\mathrm{g}$ a.i./ha; tebuconazole (Folicur, 25\% EC) was applied at a rate of $187 \mathrm{~g}$ a.i./ha, and difenoconazole (Score, $25 \% \mathrm{EC}$ ) was applied at a rate of $125 \mathrm{~g}$ a.i./ha. Fungicides (in 250 to 300 liters of water per ha) were applied with a motorized backpack sprayer at a pressure of $275 \mathrm{kPa}$ with cone-jet X6 nozzles. In one of the 1997 experiments, fungicide (in 90 to 100 liters of water per ha) was applied with a tractor-mounted boom sprayer with cone-jet X3 nozzles at a pressure of $350 \mathrm{kPa}$. The sprays did not contain spreader, sticker, or adjuvant.

Inoculation and disease assessment. A strain of D. rabiei was isolated on potato dextrose agar medium from naturally infected chickpea stems. The fungus was grown in Erlenmeyer flasks on sterilized wheat seeds at $20^{\circ} \mathrm{C}$. Fourteen-day-old cultures were used for artificial inoculations of the spreader rows in the field experiments and of the plants in the greenhouse experiments. Conidias' suspensions were prepared by adding sterile distilled water to the flasks, shaking them for several minutes, and filtering through four layers of cheesecloth. The suspensions were adjusted with a hemacytometer to the desired concentrations by adding distilled water. Tween 20 ( 1 drop per $100 \mathrm{ml}$ ) was added to the inoculum suspension as a wetting agent.

The spreader rows were artificially inoculated in 1993, 1995, 1996, and 1998. A spore suspension ( $10^{5}$ spores per ml) was applied with an air-pressure hand sprayer at $15 \mathrm{ml} / \mathrm{m}$ of plant row in early to middle February. Inoculation was done after plants in the spreader rows had been wetted by overhead irrigation. In 1994, 1997, and 1999, natural infections occurred at the experimental site. Most infections were observed on plants of cv. Sfaradit, either in the spreader rows or in the experimental plots. The source of inoculum was airborne ascospores of D. rabiei from Ascochyta-infested plant debris from nearby fields.

In all experiments (except 1993), disease severity (percent aerial plant tissue affected, including leaf and stem lesions) was visually assessed, according to the Horsfall-Barratt grading system (9). For data analyses, Horsfall-Barratt values were converted to disease percent ratings. Two individuals (the same ones for each experiment) made assessments on a whole-plot basis, and scores were averaged. Disease symptoms in the experimental plots were first observed in middle to late February in experiments conducted in 1994, 1995, and 1996; in early March 1993 and 1997; and in early April 1998 and 1999. Disease assessments were initiated soon after the first detection of Ascochyta blight symptoms in the experimental plots. Subsequent assessments were made every 5 to 10 days until late April to middle May when disease severity had stopped changing and natural senescence masked its effects. In the 1993 experiment, disease was assessed on individual plants. Ten plants were arbitrarily sampled from each experimental plot, and the number of Ascochyta blight lesions on the stem of each plant was counted. The number of stem lesions was averaged for each 
plot, and plot records were used to calculate the severity of the disease in each treatment.

Relative contributions of genotype resistance and chemical control. Six experiments were conducted from 1994 to 1999 (one experiment per year). Experiments were arranged in a randomized complete-block design with four replicates. The experiments were factorial with two main factors, each having several levels. The first factor, genotype resistance, comprised four levels: cvs. Sfaradit, Ayala, Hadas, and Bulgarit. The second factor, chemical control, comprised two levels: plots were either not treated (control) or regularly treated with fungicides. In the first four experiments, the fungicide tebuconazole was used, and difenoconazole was used for the last two. Spraying was initiated 2 to 4 days after inoculation of the spreader rows (when no disease symptoms were observed in experimental plots) or soon after the observation of Ascochyta blight symptoms from natural infection in any plot in the experiment. Subsequent sprays were applied at 10- to14-day intervals until the end of the season, four or five times total.

Postinfection application of fungicides. The efficacy of postinfection application of systemic fungicides in the management of Ascochyta blight was tested in four field experiments. One cultivar was included in each of the experiments conducted in 1993 (Sfaradit) and 1997 (Hadas) and three cultivars (Sfaradit, Ayala, and Hadas) in the 1994 and 1995 experiments. Experiments on postinfection application were located adjacent to those described above. Plot size in the 1997 experiment was $4 \times 9 \mathrm{~m}$, and a tractor-mounted boom sprayer was employed for spraying. Each experiment consisted of three or four treatments, laid out in randomized complete blocks as follows: (i) untreated control (all experiments); (ii) maneb applied on a 7-day schedule (1993, 1994, and 1995); (iii) tebuconazole (1993 and 1994) or difenoconazole (1997) applied on a preventive 14-day schedule; and (iv) tebuconazole (1993, 1994, and 1995) or difenoconazole (1997) applied as a postinfection treatment. In treatments two and three, spraying was initiated 2 to 4 days after artificial inoculation of the spreader rows or soon after the first observation of Ascochyta blight symptoms from natural infection in any of the experimental plots. Sprays in treatment four were applied after the occurrence of rain events (totaling at least $10 \mathrm{~mm}$ ) or after irrigation provided that at least 10 days had passed since the previous spray. The number of sprays applied for each treatment in each of the experiments is listed in Table 2. The occurrence of rain events and the time of irrigation are indicated in Figure 1.

Effects of the amount of irrigation on disease development and on the efficacy of the postinfection spraying treatment were tested in two field experiments in 1998 and 1999. Seeds of Sfaradit, Ayala, Hadas, and Bulgarit were sown, and the plants were cultivated as described above. Experimental plots were divided into five large blocks in 1998 and three large blocks in 1999. At the end of the rainy season (5 May 1998 and 27 April 1999), the blocks were irrigated with overhead sprinklers. One irrigation treatment was applied to each large block. The quantities of irrigation water (treatments) were $0,50,100,200$, and $300 \mathrm{~m}^{3} / \mathrm{ha}$ in 1998 and 0,50 , and $200 \mathrm{~m}^{3} / \mathrm{ha}$ in 1999. Irrigation was applied in the afternoon (1600 to $1900 \mathrm{~h}$ ) to ensure a prolonged period of foliage wetness. Although overhead irrigation is not a perfect simulation of rain, the quantities applied were comparable to 5 to $30 \mathrm{~mm}$ of rain. In each block there were 32 experimental plots $(2 \times 9 \mathrm{~m}$ each) arranged in a randomized complete-block design. There were two main factors: (i) genotype resistance comprised four levels: cvs. Sfaradit, Ayala, Hadas, and Bulgarit; and (ii) chemical control comprised two levels: no chemical treatment or treatment with difenoconazole (125 g a.i./ha) 1 or 2 days after irrigation. There were four replicates per treatment (cultivar $\times$ chemical control). Because there was only one block (replicates) for each irrigation treatment, this factor was not subjected to analysis of variance (ANOVA). The irrigation treatment was not replicated because of space limitations. The 1998 experiment, for example, consisted of 160 plots (five water quantity treatments $\times$ four cultivars $\times$ two chemical control treatments $\times$ four replicates).

Irrigation treatments were applied after the rainy season to ensure that rain did not affect the experiment. Infections resulting from irrigation treatments were observed in middle May, by which time the early-maturing cultivars had begun to senesce. Therefore, it was not always possible to distinguish between necrosis of leaves and stems caused by Ascochyta blight and necrosis resulting from natural senescence. The effects of irrigation amount and postinfection application of difenoconazole were assessed on the pods. Because most of the pods had developed after the last rain, pod infection in nonirrigated plants was low (incidence <10\%). Pod infection may serve as a good indication of the effects of irrigation amount and chemical control on foliage infection of Ascochyta blight, because these two types of symptoms are closely correlated (D. Shtienberg, unpublished data). Pod assessment was made 14 days after irrigation and spraying. One hundred pods were arbitrarily sampled from each experimental plot, and the presence of Ascochyta blight symptoms was determined visually. Disease incidence (proportion of infected pods) was used for data analysis.

Greenhouse experiments. The duration of postinfection activity of the fungicide tebuconazole was determined under controlled conditions. Chickpea seeds of susceptible cv. Sfaradit were sown in 1-liter pots filled with a mixture of sandy soil and perlite $(1: 1)$ and four or five seeds per pot. The plants were grown in a greenhouse at 20 to $25^{\circ} \mathrm{C}$ for 2 weeks. When plants were 10 to $15 \mathrm{~cm}$ high they were sprayed to run-off with a spore suspension of $D$. rabiei and covered with plastic bags (to ensure high relative humidity) for $24 \mathrm{~h}$. To test the postinfection activity of tebuconazole, potted plants were sprayed to run-off with the fungicide at a concentration of $0.05 \%$. Spraying was done 1 day before inoculation (day -1 ), on the day of inoculation (day $0,4 \mathrm{~h}$ after inoculation), and 1, 2, 3, and 4 days after inoculation (days 1, 2, 3, and 4, respectively). Each pot was sprayed with the fungicide only once. For comparison, plants were treated with the preventive fungicide maneb at a concentration of $0.25 \%$ on the same dates. Control plants were treated with water. Each treatment (fungicide $\times$ spraying time) was repeated six times, and the experiment was laid out in a randomized complete-block design. Two weeks after inoculation, the number of stem lesions per plant was counted. For data analysis, control efficacy values were calculated as outlined below. The greenhouse experiment was repeated once.

Data analyses. For some analyses, the area under the disease progress curve (AUDPC) was calculated on the basis of seasonlong disease assessments. The period used for calculating AUDPC extended from the date of inoculation (or the first appearance of disease) to the last disease assessment. AUDPC units are proportion days. For comparing AUDPC values from different experiments, the relative area under the disease progress curve (RAUDPC) was calculated by dividing the AUDPC value by the duration of the epidemic and multiplying the outcome by 100. RAUDPC units are percentages. Disease severity or RAUDPC values, recorded in treated plots $\left(D_{t}\right)$ and in untreated plots $\left(D_{u}\right)$, were used to calculate the control efficacy $\left(C E_{t}\right)$ achieved by the treatment: $C E_{t}(\%)=100-D_{t} / D_{u} \times$ 100. The contributions of genotype resistance and chemical control were estimated by comparing RAUDPC values with those recorded in untreated plots of susceptible cv. Sfaradit. In these analyses, the term relative control efficacy of the treatments (i.e., relative to RAUDPC in cv. Sfaradit) was used (22).

Data were analyzed by ANOVA and regression analyses as appropriate. Because the interaction terms between genotype resistance and fungicide treatments were significant $(P \leq 0.05)$ in all analyses, the least significant differences (LSD) are presented. For some analyses, linear regression equations were computed. In one data set, one data point lay far beyond the estimated value (calculated by the regression equation); use of a standard deviation of 4 as the threshold for selecting outliers (15) enabled this data point to be excluded from the data set. 


\section{RESULTS}

Relative contributions of genotype resistance and chemical control. The intensity of Ascochyta blight epidemics varied markedly during the 6 years of the study. Severe epidemics devel- oped in 1994, 1996, and 1997; a moderate epidemic developed in 1995; and mild epidemics developed in 1998 and 1999. Outbreaks of severe disease occurred, in most cases, 10 to 14 days after rain or irrigation events. In severe epidemics, disease severity in highly susceptible cv. Sfaradit approached $100 \% 3$ to 4 weeks after the
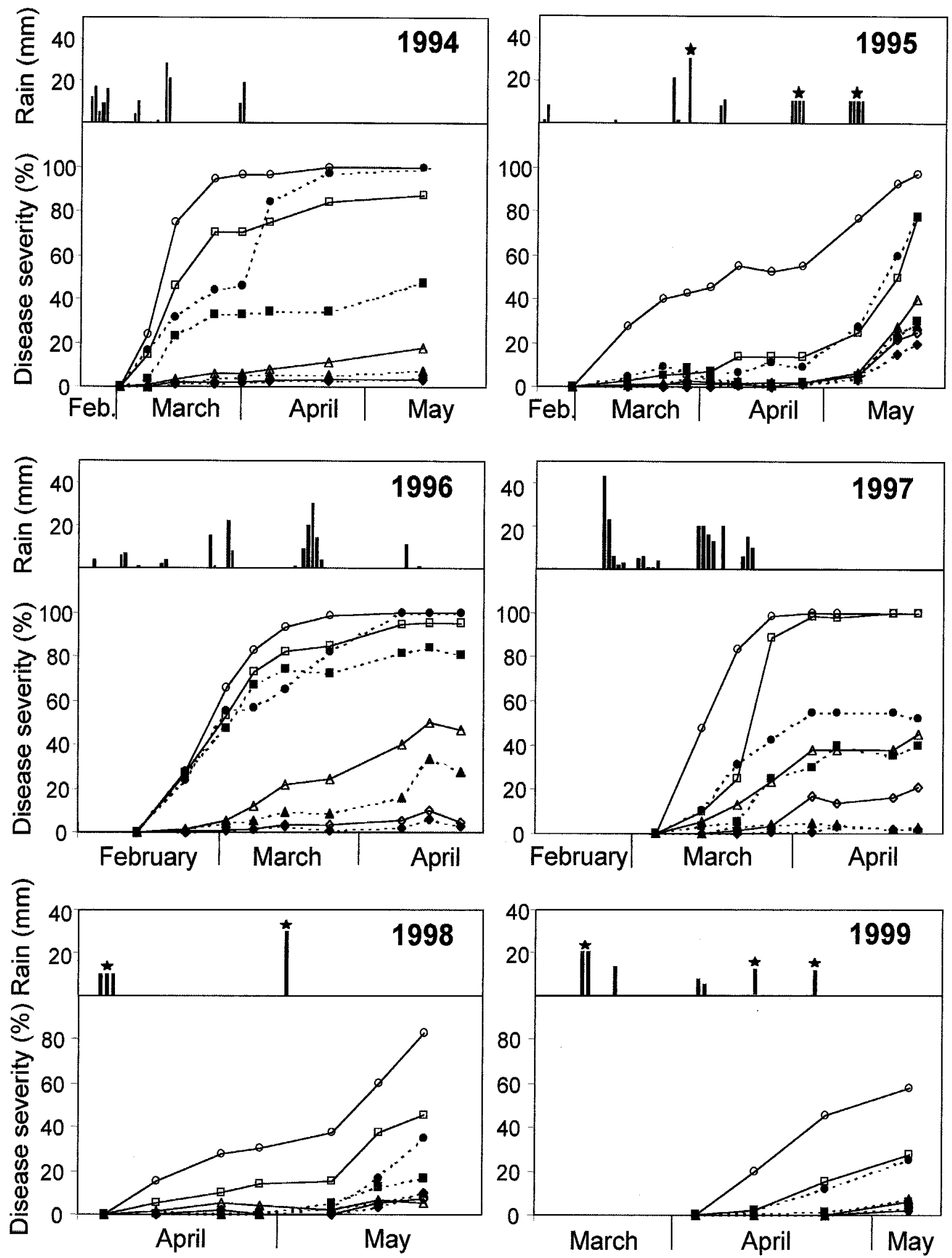

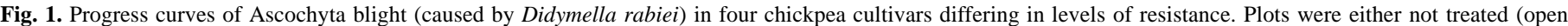

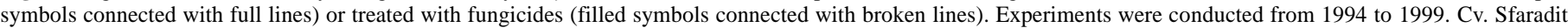

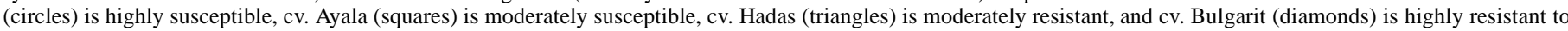

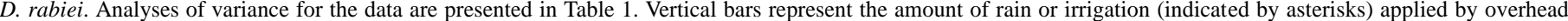
sprinklers on the corresponding dates. 
first appearance of symptoms in the experimental plots. Disease development in moderately susceptible cv. Ayala was slower, but final disease severity was high (78 to 100\%). In moderate and mild epidemics, final disease severity in plots of Sfaradit was 58 to $94 \%$, and in plots of Ayala, it was 25 to $77 \%$. Disease severity in plots of moderately resistant cv. Hadas did not exceed 50\%, even in severe epidemics, and final disease severity in plots of highly resistant cv. Bulgarit never exceeded 25\% (Fig. 1, Table 1).

The RAUDPC values in untreated plots of susceptible cv. Sfaradit were used as a measure of the conduciveness of the environment to D. rabiei. The higher the RAUDPC values, the more conducive the weather was for the pathogen. The efficacy of chemical control in susceptible cv. Sfaradit was significantly $(P<$ 0.01 ) related to the conduciveness of the environment to the pathogen. Adequate (>80\% control efficacy) disease suppression was achieved when weather supported mild epidemics, but insufficient $(<20 \%)$ control efficacy was achieved when weather supported severe epidemics (Fig. 2A, Table 1).

The contribution of genotype resistance to disease suppression in moderately susceptible cv. Ayala ranged from $<10 \%$ relative control efficacy when weather supported severe epidemics to $\approx 60 \%$ relative control efficacy when weather supported mild epidemics. The effect of chemical control was significant, and application of fungicides improved disease suppression under all conditions. The contribution of fungicides to relative control efficacy in cv. Ayala ranged from 40 to $60 \%$. Integration of chemical control with the level of genotype resistance of cv. Ayala, resulted in adequate disease suppression $(\approx 95 \%$ control efficacy) when weather supported mild epidemics, but only moderate suppression $(\approx 65 \%$ control efficacy) was observed when weather supported severe epidemics (Fig. 2B).

The level of genotype resistance in cv. Hadas resulted in control efficacy of $\approx 70 \%$ when weather supported severe epidemics. Addition of fungicides under these circumstances improved control efficacy significantly to $>95 \%$. Under conditions conducive to mild epidemics, the level of genotype resistance in cv. Hadas was sufficient to achieve adequate disease control by itself; addition of fungicide did not improve disease control, and spraying was unnecessary (Fig. 2C). The level of genotype resistance available in cv. Bulgarit was sufficient to suppress the disease adequately under all conditions, and application of fungicide to this cultivar was not needed (Fig. 2D).

Postinfection application of fungicides. Postinfection use of fungicides is effective only if the fungicides are capable of eliminating established infections. Experiments conducted in a controlled environment revealed that application of tebuconazole, up to 3 days after inoculation, resulted in disease control comparable with that provided by application of fungicide 1 day before or on the day of inoculation. Application of tebuconazole 4 days after inoculation resulted in significantly lower disease suppression com-

TABLE 1. Effects of genotype resistance and chemical control on the severity of Ascochyta blight (caused by Didymella rabiei) in chickpea

\begin{tabular}{|c|c|c|c|c|c|}
\hline \multirow[b]{2}{*}{ Year } & \multirow[b]{2}{*}{ Cultivar } & \multicolumn{2}{|c|}{$\%$ Final disease severity } & \multicolumn{2}{|c|}{$\%$ RAUDPC $^{\mathrm{x}}$} \\
\hline & & Untreated & Sprayed & Untreated & Sprayed \\
\hline \multirow[t]{5}{*}{1994} & Sfaradit & 99.7 & 99.7 & 90.5 & 69.9 \\
\hline & Ayala & 78.5 & 47.5 & 70.5 & 32.4 \\
\hline & Hadas & 17.5 & 7.2 & 8.7 & 4.6 \\
\hline & Bulgarit & 4.2 & 3.5 & 2.3 & 2.4 \\
\hline & $\operatorname{LSD}(P \leq 0.05)^{\mathrm{y}}$ & & & & \\
\hline \multirow{5}{*}{1995} & Sfaradit & 94.0 & 77.5 & 52.2 & 16.3 \\
\hline & Ayala & 77.5 & 38.3 & 32.0 & 7.2 \\
\hline & Hadas & 40.0 & 15.0 & 5.4 & 2.4 \\
\hline & Bulgarit & 25.0 & 10.0 & 4.1 & 3.7 \\
\hline & $\operatorname{LSD}(P \leq 0.05)$ & & & & \\
\hline \multirow[t]{5}{*}{1996} & Sfaradit & 100.0 & 100.0 & 73.9 & 63.9 \\
\hline & Ayala & 95.0 & 80.5 & 66.4 & 58.3 \\
\hline & Hadas & 46.7 & 27.5 & 21.6 & 10.4 \\
\hline & Bulgarit & 4.5 & 2.3 & 3.1 & 1.1 \\
\hline & $\mathrm{LSD}(P \leq 0.05)$ & & & & \\
\hline \multirow[t]{5}{*}{1997} & Sfaradit & 100.0 & 52.5 & 69.4 & 33.8 \\
\hline & Ayala & 99.8 & 40.0 & 57.9 & 18.9 \\
\hline & Hadas & 45.0 & 2.3 & 21.6 & 2.2 \\
\hline & Bulgarit & 16.3 & 2.0 & 6.7 & 1.0 \\
\hline & $\mathrm{LSD}(P \leq 0.05)$ & & & & \\
\hline \multirow[t]{5}{*}{1998} & Sfaradit & 82.5 & 35.0 & 34.6 & 5.2 \\
\hline & Ayala & 45.0 & 16.5 & 15.7 & 2.9 \\
\hline & Hadas & 5.0 & 6.0 & 3.3 & 2.1 \\
\hline & Bulgarit & 7.5 & 8.5 & 1.5 & 1.5 \\
\hline & $\mathrm{LSD}(P \leq 0.05)$ & & & & \\
\hline \multirow[t]{5}{*}{1999} & Sfaradit & 58.4 & 27.8 & 34.6 & 10.5 \\
\hline & Ayala & 25.0 & 6.2 & 10.1 & 1.7 \\
\hline & Hadas & 7.5 & 6.2 & 1.3 & 1.1 \\
\hline & Bulgarit & 8.7 & 6.2 & 1.6 & 1.1 \\
\hline & $\mathrm{LSD}(P \leq 0.05)$ & & & & \\
\hline \multirow[t]{4}{*}{ 6-year mean ${ }^{z}$} & Sfaradit & $89.1(16.5)$ & $65.4(31.7)$ & $59.2(22.6)$ & $33.3(27.8)$ \\
\hline & Ayala & $70.1(29.3)$ & $38.2(26.0)$ & $42.1(26.3)$ & $20.2(22.0)$ \\
\hline & Hadas & $27.0(19.1)$ & $10.7(9.2)$ & $10.3(9.1)$ & $3.8(3.4)$ \\
\hline & Bulgarit & $11.0(8.1)$ & $5.4(3.4)$ & $3.2(2.0)$ & $1.8(1.1)$ \\
\hline
\end{tabular}

${ }^{x}$ Relative area under the disease progress curve.

y The interaction term (cultivar $\times$ treatment) of the two-way analysis of variance was significant in all analyses according to LSD.

$\mathrm{z}$ Values in parenthesis are the standard deviation of the mean. 
pared with application of tebuconazole 3 days or less after inoculation. As expected, application of the preventive fungicide maneb one or more days after inoculation resulted in inadequate disease suppression. However, when maneb was applied before or on the day of inoculation, it suppressed the disease significantly (Fig. 3). Results of a second experiment supported these observations (data not shown).

The ability to control the disease by postinfection application of systemic fungicides was evaluated in four field experiments. Final disease severity and RAUDPC values in plots treated according to postinfection treatment did not differ significantly from those recorded in plots treated with the regular spraying schedule in all but one case (Table 2). Qualitative comparison of control efficacy values achieved by the two treatments confirmed the conclusions derived from ANOVA (Fig. 4). The theoretical line (line 1:1), indicating a perfect coincidence between control efficacy achieved by the regular and the postinfection treatments, has an intercept of 0 and slope of 1 . The regression equation that fitted the observed values had an intercept $(7.1 \%)$ that was not significantly different from $0(P=0.05)$, and a slope $(0.80)$ that was not significantly different from $1(P=0.05)$.

In this set of experiments, the systemic postinfection treatment was applied to cultivars with various levels of genotype resistance to $D$. rabiei. In general, conclusions regarding the contribution of chemical control (either regular or postinfection systemic treatments) resembled the conclusions for the first set of experiments described above (Figs. 1 and 2, Table 1). For susceptible cv. Sfaradit, the postinfection treatment contributed significantly to disease suppression during mild (1993) or moderate (1995) epidemics but not during a severe epidemic (1994). For moderately susceptible cv. Ayala, the postinfection treatment had significant effects in all situations (Table 2). For moderately resistant cv. Hadas, the postinfection treatment contributed to disease suppression significantly under severe epidemics (1994 and 1997) but not under the mild epidemic of 1995 when genotype resistance alone significantly suppressed the disease (Table 2).

In two experiments in 1998 and 1999, the effects of various amounts of irrigation applied via overhead sprinklers (simulating rain) on disease progress was tested. For susceptible cvs. Sfaradit and Ayala, addition of water at 50 and $100 \mathrm{~m}^{3} / \mathrm{ha}$ (comparable with 5 and $10 \mathrm{~mm}$ of rain, respectively) resulted in an increase in disease incidence (Fig. 5). Application of the fungicide difenoconazole 1 or 2 days after irrigation was effective and decreased disease incidence significantly, regardless of the quantity of water applied. The fungicide reduced disease incidence from 65 to $98 \%$ in cv. Sfaradit and from 83 to $97 \%$ in cv. Ayala. For moderately resistant cv. Hadas, application of water at $200 \mathrm{~m}^{3} /$ ha or more slightly increased disease incidence. Application of difenoconazole prevented pod infection in cv. Hadas. For resistant cv. Bulgarit, an application of water at $300 \mathrm{~m}^{3} / \mathrm{ha}$ (comparable with $30 \mathrm{~mm}$ of rain) did not result in any appreciable increase in disease incidence (Fig. 5).

\section{DISCUSSION}

Ascochyta blight is the major biotic constraint to the cultivation of winter-sown chickpea in the Mediterranean region. Development of adequate means to cope with this threat may enable chickpea to be sown in the winter in regions where it is not currently practical and decrease the losses caused by the pathogen in areas where winter sowing is currently employed. Results of this study demonstrate that the disease can be managed properly, even when conditions are highly conducive to the pathogen and when severe epidemics develop. The key factor for successful disease management is integration of control measures.

Genotype resistance is the primary means by which $D$. rabiei should be managed $(1,13,14)$. When the level of resistance is high (as in cv. Bulgarit), adequate disease suppression was achieved
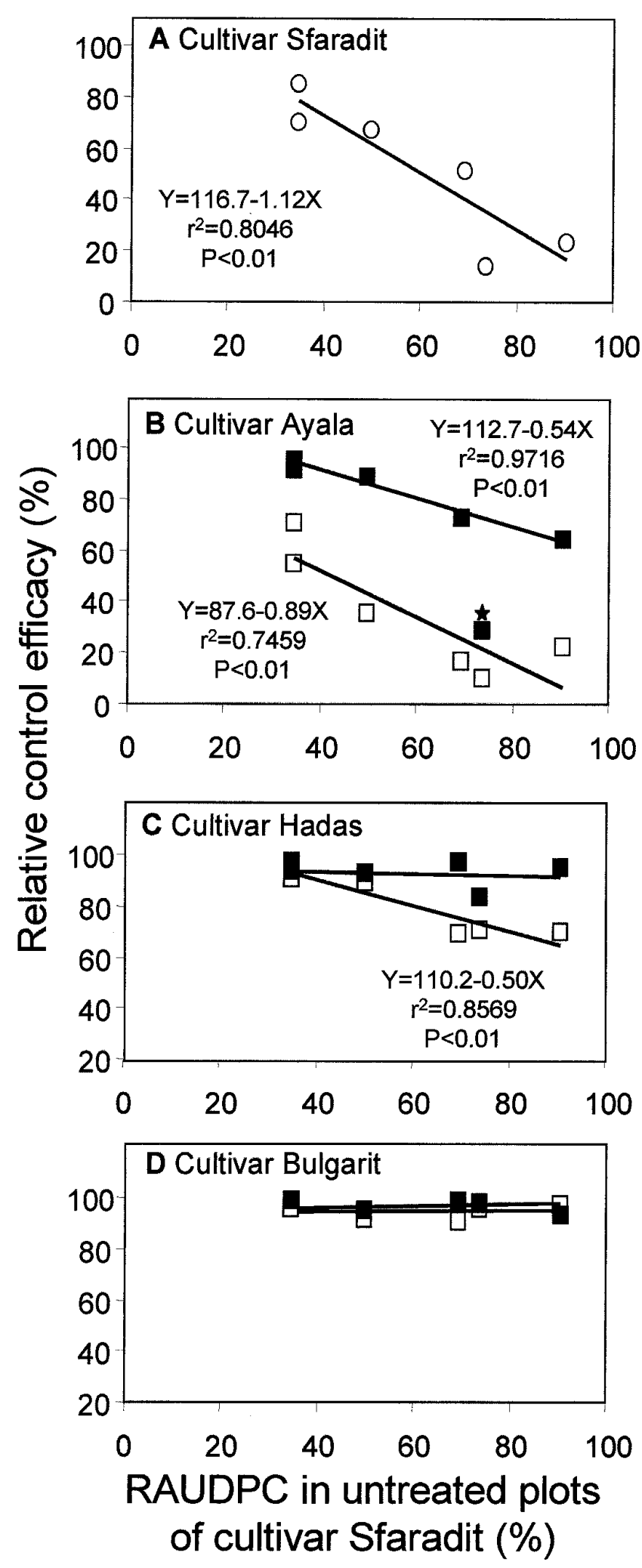

Fig. 2. Effects of genotype resistance and chemical control on the suppression of Ascochyta blight (caused by Didymella rabiei) in relation to the suitability of the environment to the pathogen (ES). The ES is expressed in terms of the relative area under the disease progress curves (RAUDPC) recorded in untreated plots of the highly susceptible cv. Sfaradit. Cv. Ayala is moderately susceptible, Hadas is moderately resistant, and Bulgarit is highly resistant to D. rabiei. A, Circles represent the sole effect of chemical control in cv. Sfaradit. B-D, Open squares represent the sole effect of genotype resistance, and filled squares represent the combined effects of genotype resistance (available in each cultivar) and chemical control. Each data point is the mean value recorded in an epidemic development over 1 year. The data point marked by an asterisk was considered an outlier and excluded from the regression analysis (using four units of standard deviation as the threshold for selecting outliers (15)). 
even when the environment was highly conducive to the pathogen and without implementation of chemical control (Table 1, Figs. 1 and 2). However, it is not uncommon that growers prefer not to use cultivars with high levels of resistance because of their lower profitability. In Israel, the color and size of chickpea grains deter-

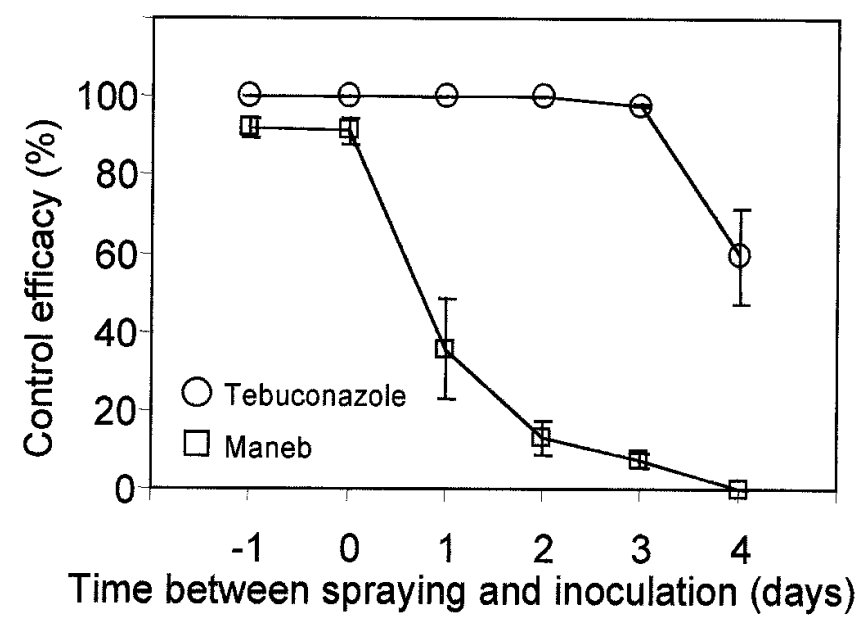

Fig. 3. Postinfection activity of the systemic fungicide tebuconazole and the preventive fungicide maneb on Ascochyta blight (caused by Didymella rabiei) in chickpea. Control efficacy in fungicide-treated plants was calculated in relation to disease severity in untreated plants. Potted plants were artificially inoculated with the pathogen at day 0 . Fungicides were applied 1 day before (day -1$)$, on the same day (day 0), or 1 to 4 days after inoculation. Bars represent the standard error of the mean of six replicates. mine their value. Thus, grains of susceptible cv. Sfaradit (white, each weighing 600 to $700 \mathrm{mg}$ ) fetch two times more than grains of highly resistant cv. Bulgarit (beige, each weighing 250 to $280 \mathrm{mg}$ ). Moreover, the fertility of cv. Bulgarit is lower than other cultivars. Consequently, growers prefer to sow cultivars with lower levels of resistance and higher economic return potential. In 1999, for example, $\approx 90 \%$ of the chickpea growing area in Israel was sown with moderately resistant cv. Hadas (beige, each weighing 430 to $470 \mathrm{mg}$ ). In some years, when conditions are highly conducive to the pathogen, the level of resistance in moderately resistant cultivars would not be sufficient to prevent epidemic development of Ascochyta blight and substantial losses of yield. In these situations, complementary actions are needed.

A possible problem of genotype resistance against $D$. rabiei is the uncertain durability of resistance. It is well established that the pathogenicity of $D$. rabiei is highly variable. Resistant cultivars may eventually become susceptible to new pathotypes of the pathogen $(1,13,18)$. Loss of resistance in chickpea cultivars has been reported in India, Pakistan, and other countries $(13,18)$. However, in some cases, cultivars remain resistant for long periods. Cv. Bulgarit, for example, identified as highly resistant in Israel in 1964 (26), has retained its resistance for 35 years and was still highly resistant to the pathogen in the experiment conducted in 1999 (Fig. 1, Table 1).

Another problem in disease management is the year-to-year variability of control efficacy. Variability results from many factors, especially variations in weather. Analysis of the data recorded over the 6 years revealed that year-to-year variation in seasonal weather (typical of Israel) influenced Ascochyta blight suppression by fungicides more than genotype resistance (Table 1). The mean control efficacy achieved by application of fungicides

TABLE 2. Effects of postinfection treatment with systemic fungicides on the severity of Ascochyta blight (caused by Didymella rabiei) in chickpea

\begin{tabular}{|c|c|c|c|c|c|}
\hline Year & Cultivar & Treatment $^{\mathrm{w}}$ & No. of sprays & $\%$ Final disease severity ${ }^{x}$ & $\%$ RAUDPC $^{\mathrm{y}}$ \\
\hline \multirow[t]{4}{*}{1993} & Sfaradit & Untreated & 0 & $11.5 \mathrm{a}^{\mathrm{z}}$ & \\
\hline & & Maneb, regular & 9 & $2.5 \mathrm{~b}$ & $\ldots$ \\
\hline & & Tebuconazole, regular & 5 & $2.4 \mathrm{~b}$ & $\ldots$ \\
\hline & & Tebuconazole, postinfection & 3 & $2.7 \mathrm{~b}$ & $\cdots$ \\
\hline \multirow[t]{12}{*}{1994} & Sfaradit & Untreated & 0 & $100.0 \mathrm{a}$ & $89.8 \mathrm{a}$ \\
\hline & & Maneb, regular & 9 & $99.5 \mathrm{a}$ & $81.5 \mathrm{ab}$ \\
\hline & & Tebuconazole, regular & 5 & $97.2 \mathrm{a}$ & $70.3 \mathrm{~b}$ \\
\hline & & Tebuconazole, postinfection & 3 & $99.7 \mathrm{a}$ & $65.8 \mathrm{~b}$ \\
\hline & Ayala & Untreated & 0 & $98.7 \mathrm{a}$ & $86.5 \mathrm{a}$ \\
\hline & & Maneb, regular & 9 & $59.2 \mathrm{~b}$ & $53.3 \mathrm{bc}$ \\
\hline & & Tebuconazole, regular & 5 & $54.7 \mathrm{~b}$ & $44.0 \mathrm{c}$ \\
\hline & & Tebuconazole, postinfection & 3 & $70.0 \mathrm{~b}$ & $57.0 \mathrm{~b}$ \\
\hline & Hadas & Untreated & 0 & $20.0 \mathrm{a}$ & $13.2 \mathrm{a}$ \\
\hline & & Maneb, regular & 9 & $7.5 \mathrm{~b}$ & $3.6 \mathrm{~b}$ \\
\hline & & Tebuconazole, regular & 5 & $6.7 \mathrm{~b}$ & $2.9 \mathrm{~b}$ \\
\hline & & Tebuconazole, postinfection & 3 & $8.0 \mathrm{~b}$ & $3.9 \mathrm{~b}$ \\
\hline \multirow[t]{9}{*}{1995} & Sfaradit & Untreated & 0 & $97.2 \mathrm{a}$ & $49.7 \mathrm{a}$ \\
\hline & & Maneb, regular & 10 & $77.5 \mathrm{~b}$ & $16.3 \mathrm{~b}$ \\
\hline & & Tebuconazole, regular & 4 & $73.3 \mathrm{~b}$ & $17.9 \mathrm{~b}$ \\
\hline & Ayala & Untreated & 0 & $77.5 \mathrm{a}$ & $15.9 \mathrm{a}$ \\
\hline & & Maneb, regular & 10 & $30.0 \mathrm{~b}$ & $5.7 \mathrm{~b}$ \\
\hline & & Tebuconazole, postinfection & 4 & $32.5 \mathrm{~b}$ & $5.2 \mathrm{~b}$ \\
\hline & Hadas & Untreated & 0 & $27.5 \mathrm{a}$ & $5.4 \mathrm{a}$ \\
\hline & & Maneb, regular & 10 & $25.0 \mathrm{a}$ & $5.2 \mathrm{a}$ \\
\hline & & Tebuconazole, postinfection & 4 & $10.0 \mathrm{a}$ & $4.2 \mathrm{a}$ \\
\hline \multirow[t]{3}{*}{1997} & Hadas & Untreated & 0 & $32.2 \mathrm{a}$ & $26.6 \mathrm{a}$ \\
\hline & & Difenoconazole, regular & 3 & $17.1 \mathrm{~b}$ & $15.7 \mathrm{~b}$ \\
\hline & & Difenoconazole, postinfection & 1 & $16.4 \mathrm{~b}$ & $17.8 \mathrm{~b}$ \\
\hline
\end{tabular}

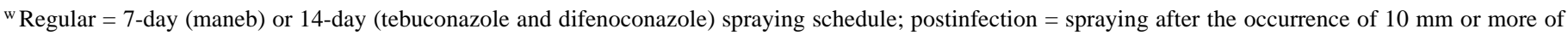
rain or after overhead irrigation, provided that at least 10 days passed since the previous spray.

${ }^{x}$ In 1993, the number of stem lesions per stem was assessed. In the other experiments, values represent the proportion of leaf area and stems infected by the disease.

y Relative area under the disease progress curve.

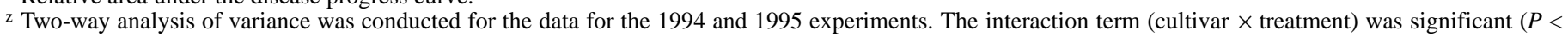
$0.05)$. Numbers within a column (for each cultivar in each experiment) followed by the same letter are not significantly different $(P=0.05)$, as determined by Fisher's protected LSD. 
in cv. Sfaradit was $51.5 \%$, but the results were highly variable (coefficient of variation $[\mathrm{CV}]=54.7 \%$ ). The level of genotype resistance in Ayala resulted in $35.5 \%$ disease suppression (based on RAUDPC) compared with Sfaradit, but the variation was high $(\mathrm{CV}=66.7 \%)$. Application of chemical control to plots of cv. Ayala improved disease suppression to $71.8 \%$ and slightly decreased the variability $(\mathrm{CV}=38.2 \%)$. The level of genotype resistance in cv. Hadas resulted in control efficacy of $84.4 \%$, but variability was still relatively high $(\mathrm{CV}=13.7 \%)$. Improved control efficacy ( $94.0 \%$ control) and lower variability $(\mathrm{CV}=4.3 \%)$ were obtained in fungicide-treated plots. For the resistance level in cv. Bulgarit, genotype resistance provided $94.5 \%$ control with very low variation among years $(\mathrm{CV}=2.9 \%)$. Addition of chemical control did not significantly improve disease suppression (control efficacy = $96.6 \%)$ or lower variation $(\mathrm{CV}=2.2 \%$; Table 1$)$.

The relative contributions of genotype resistance and chemical control to disease suppression may differ according to the host and parasite. For example, effects of genotype resistance and fungicide on early and late blight in potatoes (caused by Alternaria solani and Phytophthora infestans, respectively) were quantified by computer simulation models (24). Moderate resistance to early blight had a 1.5-fold greater effect than preventive fungicide used for early blight suppression. However, the contribution of fungicides to the suppression of late blight was 3.6-fold greater than that of genotype resistance to $P$. infestans. One objective of the present study was to compare the relative contributions of genotype resistance and chemical control with the suppression of Ascochyta blight. The comparison was based on the level of genotype resistance present in commercial cultivars (e.g., Hadas and Bulgarit) and the current efficacy of registered fungicides (e.g., tebuconazole and difenoconazole). Should more resistant cultivars be released or more effective fungicides be registered, the relative contributions of these measures would need to be reestimated. In the 6 years of the study, the level of genotype resistance available in cv. Bulgarit was 1.4 to 7.1 times as great as the effects of the fungicides used ( $2.8 \pm 1.06$; mean \pm standard error). For the level of resistance available in cv. Hadas, the corresponding range was 1.1 to $5.2(2.4 \pm 0.79)$. The conclusion-genotype resistance should be the primary means of managing Ascochyta blight, and chemical control should be implemented as an additional means, when needed.

Because the contribution of chemical control was significant, the next step was to optimize its use. Prophylactic application of

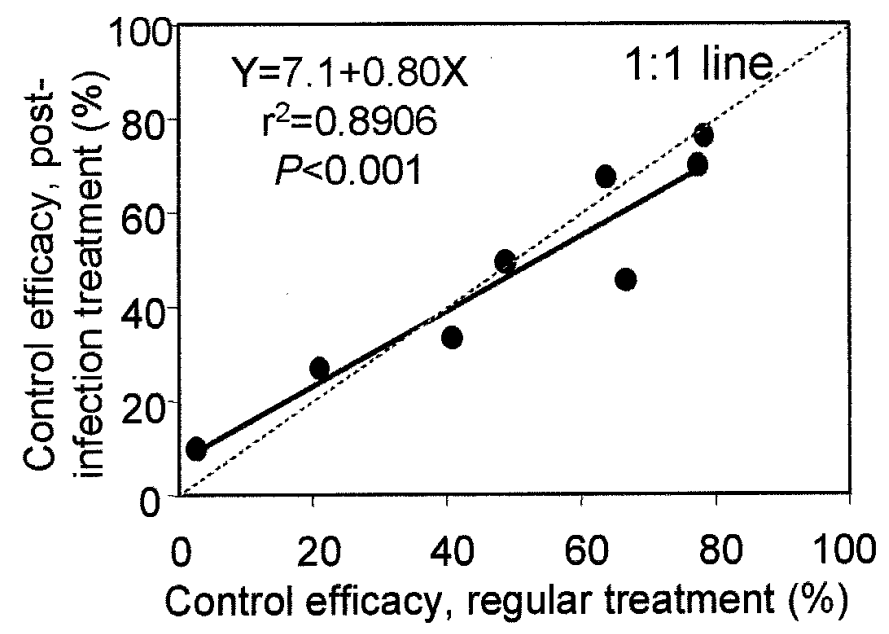

Fig. 4. Comparison of the efficacy of control of Ascochyta blight (caused by Didymella rabiei) in chickpea achieved by application of systemic fungicides as a postinfection treatment with that achieved by regular sprays. Each data point represents the results recorded for one cultivar in experiments conducted from 1993 to 1997 (Table 2). Solid line indicates the regression equation describing the fit between observed values. Dashed line (line 1:1) indicates the relationship for perfect coincidence between the two variables. preventive fungicides is not a practical strategy in winter sowing, because of the long period of protection needed and the consequent large number of sprays. In the present study, we tested the possibility of relying on postinfection rather than prophylactic application of fungicides. The duration of the postinfection activity of tebuconazole was up to 3 days (Fig. 3), and application of this systemic fungicide enabled suppression of Ascochyta blight as effectively as regular spray application (Table 2, Fig. 3). The number of sprays applied in the postinfection treatment in the four experiments ranged from 1 to $4(2.7 \pm 0.63)$, compared with 9 to $10(9.3 \pm 0.33)$ protective fungicide sprays and 3 to $5(4.3 \pm 0.66)$ systemic fungicide sprays applied in the regular schedule treatment (Table 2).

Spores of D. rabiei are dispersed in water droplets during rain and overhead irrigation. The mechanism of spore splash in water droplets is complex, and several factors affect the number of spores dispersed and the distance of dispersal. Among these factors are the amount of rain, intensity and duration, droplet size and distribution, and wind speed $(6,11,23,27)$. Another factor that governs spore dispersal is the level of resistance available in the cultivated cultivar. It is logical to assume that a certain number of dispersed spores would result in a more severe disease in a susceptible cultivar than in a highly resistant one. In previous studies, where systemic fungicides were applied as a postinfection treatment $(3,23)$, and also in some of the experiments reported here (Table 2), these factors were not considered. Based on results reported in Figure 5, however, it may be concluded that both the level of genotype resistance and the quantity of rain should be taken into account in deciding whether to apply a postinfection spray. One way to interpret the results is to define a rain-quantity threshold for each range of genotype resistance level. For example, $5 \mathrm{~mm}$ of rain may be used as a threshold for application in highly susceptible cultivars, whereas thresholds for moderately susceptible and moderately resistant cultivars could be 10 and $30 \mathrm{~mm}$, respectively. Spraying of highly resistant cultivars is not needed (Fig. 5). These thresholds need to be tested and confirmed in field experiments before being used by chickpea growers.

Based on this study, we conclude that winter sowing of chickpea is feasible in the Middle East, when adequate suppression of Ascochyta blight is achieved. The principal measure for disease

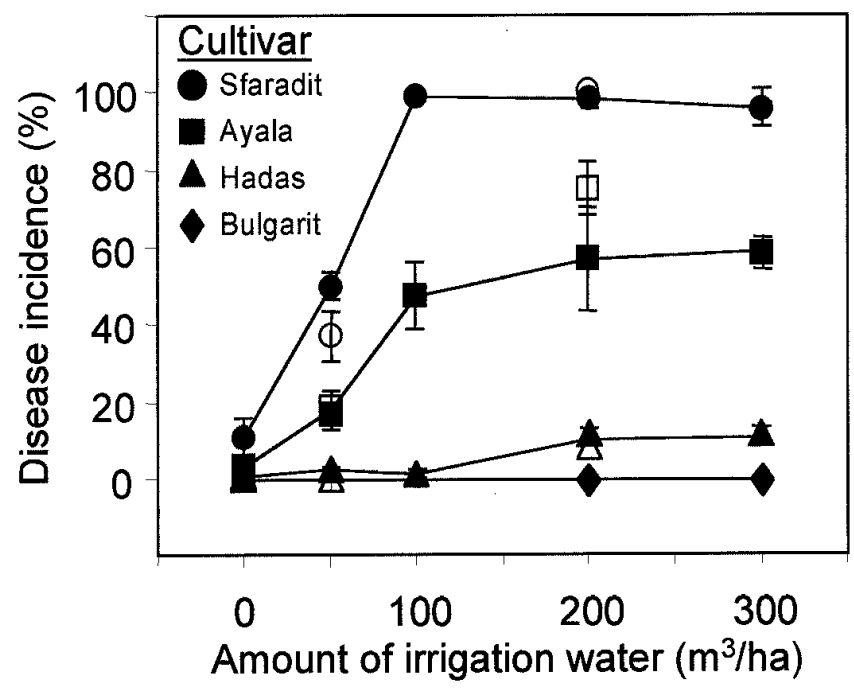

Fig. 5. Effects of the amount of added water applied via overhead sprinklers on the incidence of Ascochyta blight (caused by Didymella rabiei) in four chickpea cultivars. Disease incidence was recorded on pods. Cv. Sfaradit is highly susceptible, cv. Ayala is moderately susceptible, cv. Hadas is moderately resistant, and cv. Bulgarit is highly resistant to D. rabiei. Filled symbols reflect the 1998 experiment; open symbols reflect the 1999 experiment. Bars represent the standard error of the mean of four replicates. 
management is genotype resistance, and chemical control should be applied as a complementary measure when needed. Cultivars to be sown should possess (at least) the level of genotype resistance found in cv. Hadas. Chemical control should rely on application of systemic fungicides as a postinfection treatment after rain episodes. Following this strategy will not only result in adequate management of Ascochyta blight but will also enable the year-toyear variability in control efficacy to be reduced.

\section{ACKNOWLEDGMENTS}

Contribution 524/99 from Agricultural Research Organization, Institute of Plant Protection, Bet-Dagan, Israel.

\section{LITERATURE CITED}

1. Akem, C. 1999. Ascochyta blight of chickpea: Present status and future priorities. Int. J. Pest Manag. 45:131-137.

2. Bannon, F. J., and Cooke, B. M. 1998. Studies on dispersal of Septoria tritici pycnidiospores in wheat-clover intercrops. Plant Pathol. 47:49-56.

3. Cook, R. J. 1977. Effect of timed fungicide sprays on yield of winter wheat in relation to Septoria infection period. Plant Pathol. 26:30-34.

4. Diekmann, M. 1992. Use of climatic parameters to predict the global distribution of Ascochyta blight on chickpea. Plant Dis. 76:409-412.

5. FAO. 1989. Production Yearbook 1988. Vol. 42. Food and Agriculture Organization of the United Nations, Rome.

6. Fitt, B. D. L., McCartney, H. A., and Walklate, P. J. 1989. The role of rain in dispersal of pathogen inoculum. Annu. Rev. Phytopathol. 27:241270.

7. Fitzell, R. D., and Peak, C. M. 1989. Management strategies for control of anthracnose and bacterial black spot of mango in Northern New South Wales. Acta Hortic. 231:513-517.

8. Hanounik, S. 1980. Influence of host genotype and chemical treatment on severity of Ascochyta blight in chickpea. Int. Chickpea Newsl. 2:13.

9. Horsfall, J. G., and Barratt, R. W. 1945. An improved grading system for measuring plant disease. (Abstr.) Phytopathology 35:655.

10. Kaiser, W. J., and Muehlbauer, F. J. 1988. An outbreak of Ascochyta blight of chickpea in the Pacific Northwest, USA, in 1987. Int. Chickpea Newsl. 18:16-17.

11. Madden, L. V. 1997. Effects of rain on splash dispersal of fungal pathogens. Can. J. Plant Pathol. 19:225-230.

12. Navas-Cortés, J. A., Pérez-Artés, E., Jiménez-Diaz, R. M., Llobell, A., Bainbridge, B. W., and Heale, J. B. 1998. Mating type, pathotype, and RAPDs analysis in Didymella rabiei, the agent of Ascochyta blight of chickpea. Phytoparasitica 26:199-212.
13. Nene, Y. L. 1982. A review of Ascochyta blight of chickpea. Trop. Pest Manag. 28:61-70.

14. Nene, Y. L., and Reddy, M. V. 1987. Chickpea diseases and their control. Pages 233-270 in: The Chickpea. M. V. Saxena and K. B. Singh, eds. $\mathrm{CAB}$ International, Oxford.

15. Neter, J., Wasserman, W., and Kutner, M. H. 1985. Applied Linear Statistical Models. Richard D. Irwin, Homewood, IL.

16. Parker, S. K., Gleason, M. L., and Nutter, F. W., Jr. 1995. Influence of rain events on spatial distribution of Septoria leaf spot of tomato. Plant Dis. 79:148-152.

17. Reddy, M. V., and Kabbabeh, S. 1985. Pathogenic variability in Ascochyta rabiei (Pass.) Lab. in Syria and Lebanon. Phytopathol. Mediter. 24:265-266.

18. Reddy, M. V., Nene, Y. L., Singh, G., and Bashir, M. 1990. Strategies for management of foliar diseases of chickpea. Pages 117-127 in: Chickpea in the Winter. H. A. van Rheemen and M. C. Saxena, eds. ICRISAT, Andhra Pradesh, India.

19. Reddy, M. V., and Singh, K. B. 1990. Management of Ascochyta blight of chickpea through integration of host plant tolerance and foliar spraying of chlorothalonil. Ind. J. Plant Prot. 18:65-69.

20. Saxena, M. C., and Singh, K. B. 1984. Ascochyta blight and Winter Sowing of Chickpeas. Martinus Niijhoff, Zoetemeer, the Netherlands.

21. Schuepp, H., Bosshard, E., and Siegfried, W. 1990. Fungicide application according to infection periods, a must for integrated scab control. Acta Hortic. 285:175-186.

22. Shtienberg, D., Blachinsky, D., Kremer, Y., Ben-Hador, G., and Dinoor, A. 1995. Integration of genotype and age-related resistance to reduce fungicide use in management of Alternaria diseases of cotton and potato. Phytopathology 85:95-102.

23. Shtienberg, D., Dinoor, A., and Marani, A. 1990. Wheat disease control advisory, a decision support system for management of foliar disease of wheat in Israel. Can. J. Plant Pathol. 12:195-203.

24. Shtienberg, D., and Fry, W. E. 1990. Quantitative analysis of host resistance, fungicide and weather effects on potato early and late blight using computer simulation models. Am. Potato J. 67:277-286.

25. Singh, K. B., Malhotra, R. S., Saxena, M. C., and Bejiga, G. 1997. Superiority of winter sowing over traditional spring sowing of chickpea in the Mediterranean region. Agron. J. 89:112-118.

26. Solel, Z., and Kostrinski, J. 1964. The control of Ascochyta anthracnose of chickpea. Phytopathol. Mediter. 3:119-120.

27. Sutton, T. B. 1981. Production and dispersal of ascospores and conidia by Physalospora obtusa and Botryosphaeria dothidea in apple orchards. Phytopathology 71:584-589.

28. Trapero-Casas, A., and Kaiser, W. J. 1992. Influence of temperature, wetness period, plant age, and inoculum concentration on infection and development of Ascochyta blight of chickpea. Phytopathology 82:589596. 